\title{
25 Research Suare \\ The causes and frequency of kidney allograft failure in a low-resource setting: Data from Iraqi Kurdistan
}

\author{
Alaa Abbas Ali \\ University of Sulaymaniyah \\ Safaa E Almukhtar \\ University of Kurdistan Hewler \\ Kais H Abd \\ University of Duhok \\ Zana Sidiq M Saleem \\ University of Duhok \\ Dana A Sharif \\ University of Sulaymaniyah \\ Michael D Hughson ( $\nabla$ hughsonmichaeld@gmail.com ) \\ University of Sulaymaniyah
}

\section{Research Article}

Keywords: kidney transplantation, kidney allograft pathology, allograft rejection, acute and chronic allograft failure

Posted Date: March 3rd, 2021

DOl: https://doi.org/10.21203/rs.3.rs-233389/v1

License: (c) (i) This work is licensed under a Creative Commons Attribution 4.0 International License.

Read Full License

Version of Record: A version of this preprint was published at BMC Nephrology on August 7th, 2021. See the published version at https://doi.org/10.1186/s12882-021-02486-9. 


\section{Abstract \\ Background}

In the developing world, transplantation is the most common long-term treatment for patients with endstage renal disease, but rates and causes of graft failure are uncertain.

\section{Methods}

In 2019, in Iraqi Kurdistan, 301 of 871 renal transplant patients had indicated graft biopsies. Outcomes were followed over the subsequent year of 2020.

\section{Results}

The post-transplantation time ranged from one day to 18 years. All donors were living. Approximately $15 \%$ of transplants were preemptive. Pretransplant hemodialysis (HD) was twice weekly and less than one year. The median recipient age was 39 (IQR 28 to 48) years. 5.5\% of recipients had previous transplants; $3.7 \%$ had pretransplant donor-specific antibodies (DSA). The Kaplan-Meier estimated graft failure rates for all-cause, return to HD, and death with functional graft (DWFG) were $9.1 \%, 6.3 \%$, and $2.9 \%$ at one year and $23.8 \%, 6.3 \%$, and $7.4 \%$ at five years. The median death-censored graft survival was 15 years. The most frequent biopsy diagnoses associated with graft failure were interstitial fibrosis and tubular atrophy (IF/TA) (23.1\%), transplant glomerulopathy (13.7\%), and acquired active antibodymediated rejection $(11.1 \%)$. The significant predictors of graft loss were $C 4 d+$ biopsies $(P<0.01)$ and advanced IF/TA $(P<0.001)$.

\section{Conclusions}

These Iraqi patients had estimated graft failure rates similar to the United States (US) Renal Data System living-donor outcomes reported for the year 2000. The inability to approach recent US graft survivals may owe to inadequate pretransplant dialysis. Nevertheless, prolonged survival made chronic disorders and acquired DSA the leading causes of graft failure and is creating a need for second transplants.

\section{Introduction}

An estimated $80 \%$ of the worlds' noncommunicable diseases, including chronic kidney disease (CKD), is found in low and middle-income countries [1]. As CKD progresses to end-stage renal disease (ESRD), developing nations face an increased burden of expensive care. Because of the cost and complexity of hemodialysis, kidney transplantation is the most frequently used maintenance therapy for ESRD in most of the world [2,3]. Historically, high rates of acute rejection and the cardiovascular and infectious complications of corticosteroid immunosuppression were the principal obstacles to kidney 
transplantation. Over the past four decades, calcineurin inhibitors (CNI) have decreased the frequency and severity of T cell-mediated rejection (TCMR), and patients can have a reasonably normal lifestyle, at least in the short-term [2, 3]. In most of the Middle and Near East, the standard practice model screens for pre-existing donor-specific antibodies (DSA) and selects mainly non-sensitized patients for transplantation $[4,5]$. Nephrologists accept chronic allograft changes as generic complications of engraftment and only recently have recognized the importance of de novo antibody-mediated rejection (AMR).

CNI-based immunosuppressive regimens have produced a notable improvement in one- and five-year graft survival, but similar gains at ten years and beyond are limited $[6,7,8]$. While cell-mediated rejection is mostly preventable and treatable, T cell therapies have little influence on AMR, and AMR is becoming a frequent cause of late graft loss $[9,10]$.

In the modern era of immunosuppression, investigations into the causes of transplant failure initiated by El Zoghby et al. [7] pointed out that a specific diagnosis could usually be assigned to a lost kidney. These authors found that transplant glomerulopathy (TG) was a common cause of late graft failure, and they considered TG an alloimmune disorder. Subsequently, The recognition of $\mathrm{C} 4 \mathrm{~d}+$ and $\mathrm{C} 4 \mathrm{~d}$ - forms of AMR lead to the 2017 revision of the Banff Classification of Renal Allograft Pathology [10, 11, 12]. This classification provides criteria for diagnosing acute and chronic AMR and regards TG as a C4d-antibody disease $[10,11,12]$.

Renal transplantation in Iraq is in transition. Until 2003, Baghdad was the center. War then forced many surgeons and nephrologists into the north's Kurdish region or out of the country [13,14]. Most transplant centers have pretransplant antibody and HLA testing, but the availability of continuous supplies and expertise in the interpretation of results present challenges. The central government supports the cost of immunosuppressive therapy, yet financial shortfalls are a constant problem that shifts costs periodically onto the patient and strains compliance. These may be considered deficiencies in transplant practice, but they are common in most developing countries. CNI-based immunotherapy has certainly reduced acute TCMR, but the remaining causes and outcomes of graft dysfunction are not generally appreciated $[4,5]$.

This study investigates the frequency of transplant biopsy diagnoses and their effects on graft survival in the middle income but technically still developing country of Iraq.

\section{Material And Methods}

\section{Patients and sample collection}

The nephrology services of the Kurdish region of Iraq are located in the cities of Dohuk, Erbil (Hawler), and Sulaimania and serve approximately 5,200,000 people. From January 1 to December 31, 2019, the services registered 871 renal transplant patients. 
Preemptive transplantation comprised approximately $15 \%$ of procedures. For most patients, dialysis was between two to four months, and for all patients, dialysis was less than one year. The standard dialysis schedules throughout Iraq are four hours sessions, twice a week. All dialysis is in-center hemodialysis.

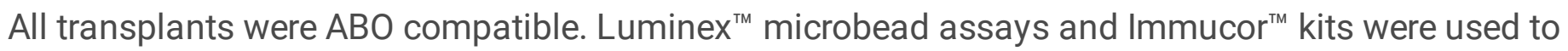
screen patients for donor-specific antibodies (DSA) and type patients and donors for 51 HLA-A, HLA-B, and HLA-DR antigens. Virtual cross-matching was performed prior to transplantation. Patients with pretransplant DSA were treated with ATG, plasmapheresis, and intravenous immunoglobulin and transplanted when the mean fluorescent intensity of the DSA became undetectable.

The most frequent combination of immunosuppressive therapy was tacrolimus or cyclosporin, mycophenolate mofetil (MMF), and corticosteroids. Episodes of acute TCMR were treated with corticosteroids and, if not responsive, with anti-thymocyte globulin (ATG). T cell depletion with ATG was routinely provided at the time of transplantation.

In 2019, the central renal biopsy laboratory in Sulaimania processed and evaluated 337 kidney allograft biopsies from 301 patients. Biopsies were performed for the clinical indications of primary nonfunction (14.1\%), deterioration of graft function (77.9\%), and proteinuria (7.9\%). Recorded patient data consisted of age, gender, history of diabetes, time post-transplantation, serum creatinine, proteinuria, immunosuppressive regimen, source of the donor, and the presence or absence of DSA. For biopsied patients, submission forms indicated compliance with immunosuppression for 252 patients (83.7\%) and noncompliance for 19 patients (6.3\%). Compliance was not stated for 30 patients (10.0\%).

\section{Patient follow-up}

\section{Biopsies}

Biopsies were studied by light microscopy in serial sections using hematoxylin and eosin, periodic acid Shiff (PAS), Masson trichrome, and Jones periodic acid-methenamine silver stains. Electron microscopy was not performed on any biopsy. Direct immunofluorescence (IF) was performed on frozen sections using fluorescein-conjugated anti-human IgG, IgM, IgA, C3, and C1q (DAKO, Santa Clara, CA). C4d staining was performed by indirect IF on frozen sections using a monoclonal anti-C4d antibody (Bio-Rad, Inc).

Diagnoses and the semiquantitative scoring of histologic lesions were based on the Banff 2017 Classification of Renal Allograft Pathology [11]. The diagnoses were categorized into acute kidney injury (AKI), acute TCMR, chronic active TCMR, active AMR, interstitial fibrosis and tubular atrophy (IF/TA), CNI toxicity, recurrent or de novo kidney disease (KD), BK nephropathy, and acute pyelonephritis. Acute TCMR included borderline rejection. Active AMR was defined by the presence of C4d deposition in peritubular capillaries and included mixed acute TCMR with active AMR. We placed biopsies in the category of transplant glomerulopathy (TG) when they demonstrated double contour glomerular basement membranes (GBM) in the absence of $\mathrm{C} 4 \mathrm{~d}$ peritubular capillary staining after excluding thrombotic microangiopathy or glomerulonephritis as reasons for the glomerular changes [11]. Acute tubular 
necrosis and histologically normal biopsies for patients with diminished graft function were classified as AKI. Thirty-six patients had more than one biopsy, with the earliest biopsy being used for the diagnosis.

\section{Statistical procedures}

The continuous variables of age, time post-transplant (in months), and serum creatinine were not normally distributed and are expressed as the median and interquartile range (IQR). Graft failure estimates used Kaplan Meier functions. All survival consisted of DWFG and HD. Death-censored outcomes consisted of HD. Proportional differences between discrete variables were analyzed by Chisquare or Fisher Exact tests. Spearman correlations evaluated the relationships between time of transplantation and scores for IF/TA and TG. Reverse step-wise logistic regression tested the significance of the independent variables of age, sex, donor source, IF/TA, C4d positive IF, AKI, and acute TCMR to the outcomes of HD or DWFG, with variables eliminated if $P \geq 0.10$. Differences were considered significant at $P<0.05$. Data analysis used IBM SPSS 26 (Armonk, NY).

\section{Results}

\section{Patient demographics}

Patient characteristics are summarized in Table 1. Median patient age was 39 (IQR 28-48), with 19.5\% being older than 50 years of age and $1.8 \% \geq 65$ years old. Recipients were $77.6 \%$ male; $6.6 \%$ were diabetic. All donors were living; $16.2 \%$ were related; $5.5 \%$ of patients were previously transplanted; and 3.7\% had pretransplant donor-specific antibodies (DSA). Patients were biopsied from one day to 18 years post-transplant. The median time for biopsy post-transplantation was 150 (IQR 30-940) days.

Table 1: Clinical characteristic of recipients 


\begin{tabular}{|ll|}
\hline Characteristic & value \\
\hline Median age, years & 39 (IQR 28-48) \\
\hline M0 years old & $19.5 \%$ \\
\hline Males & $77.6 \%$ \\
\hline Living donor & $6.6 \%$ \\
\hline Related donor & $100 \%$ \\
\hline Serum creatinine at biopsy (mg/dl) & $16.2 \%$ \\
\hline Previous transplant & $2.0($ IQR 1.6-2.6) \\
\hline Pretransplant DSA positive & $5.5 \%$ \\
\hline Noncompliant & $3.7 \%$ \\
\hline Time of biopsy post-transplantation, days & $6.6 \%$ \\
\hline Maintenance immunosuppression & 150, range 1 to 6570 \\
\hline CNI (tacrolimus/cyclosporine), MMF, steroid & $62.1 \%$ \\
\hline CNI (tacrolimus/cyclosporine), steroid & $37.9 \%$ \\
\hline Indication for biopsy: & \\
\hline Primary nonfunction & $14.1 \%$ \\
\hline Deterioration of graft function & $77.9 \%$ \\
\hline Proteinuria & $7.9 \%$ \\
\hline
\end{tabular}

Abbreviations: Continuous variables of age and serum creatinine and time of biopsy are expressed as median and interquartile range. IQR, interquartile range. CNI: calcineurin inhibitor (tacrolimus/cyclosporine); MMF:

mycophenolate mofetil; DSA, Donor-specific antibody.

In 2019, 204 patients had biopsies $\leq 365$ days after transplantation (early biopsies) and 97 patients after 365 days (late biopsies). The follow-up identified an additional 131 patients from 2019 that were biopsied in 2020. The 2020 biopsies used in this study had a median post-transplant time of 1095 (IQR 450 to 2464) days and did not include any specimens from patients transplanted after January 1, 2020. 
Pathology results

Figure 2 shows the distribution of 2019 diagnoses. The most common diagnosis was acute TCMR at $23.1 \%$, followed by $\mathrm{AKI}$ at $14.8 \%$, IF/TA at $11.4 \%$, recurrent or de novo $\mathrm{KD}$ at $8.6 \%$, $\mathrm{TG}$ at $7.6 \%$, and $\mathrm{CNI}$ toxicity at $6.9 \%$. Other specific diagnoses occurred at a frequency of less than $4 \%$. Active C4d+ AMR was diagnosed in $8.6 \%$ of patients.

Twenty-three patients were diagnosed with recurrent or de novo KD, and eleven of these 23 were FSGS. All FSGS occurred in the late biopsy period over a range of 730 to 3650 days.

Nineteen patients were diagnosed with CNI toxicity. In the early biopsy period, CNI toxicity consisted of a TMA $(n=11)$ or isometric tubular vacuolization $(n=1)$. In the late biopsy period $(n=7), C N I$ toxicity consisted of IF/TA with nodular arteriolar hyalinosis and sometimes segmental glomerulosclerosis.

Table 2 shows the distribution of diagnoses in early and late biopsies. Most patients with AKI and all patients with cortical infarction were found in early biopsies. Seventeen percent of AKI was seen after 100 days, and $3 \%$ after 12 months. These later AKI biopsies did not show features of CNI toxicity or infection, and the cause was unknown.

Table 2: Pathological diagnoses in early and late transplant biopsies.

\begin{tabular}{|llll|}
\hline Pathological lesions & $\begin{array}{l}\text { Early biopsies sone year } \\
(\mathrm{n}=204)\end{array}$ & $\begin{array}{l}\text { Late biopsies > one year } \\
(\mathrm{n}=97)\end{array}$ & $\begin{array}{c}\text { Early vs } \\
\text { Late } \\
P \text {-value }\end{array}$ \\
\hline AKI & $56(27.5 \%)$ & $2(2.1 \%)$ & $<0.001$ \\
\hline Infarction & $8(3.9 \%)$ & $9(1.0 \%)$ & 0.34 \\
\hline Acute TCMR & $69(33.8 \%)$ & $9(9.3 \%)$ & $<0.001$ \\
\hline AMR C4d+ & $17(8.3 \%)$ & $6(6.2 \%)$ & 0.98 \\
\hline Chronic TCMR & $5(2.5 \%)$ & $19(19.6 \%)$ & 0.22 \\
\hline TG & $4(2.0 \%)$ & $23(23.7 \%)$ & $<0.001$ \\
\hline IF/TA & $13(6.4 \%)$ & $7(9.5 \%)$ & $<0.001$ \\
\hline $\begin{array}{l}\text { CNI toxicity } \\
\text { Recurrent or de novo } \\
\text { KD }\end{array}$ & $8(3.9 \%)$ & $17(17.5 \%)$ & 0.87 \\
\hline Acute pyelonephritis & $7(3.4 \%)$ & $1(1.0 \%)$ & 0.001 \\
\hline $\begin{array}{l}\text { BK virus } \\
\text { nephropathy }\end{array}$ & $5(2.5 \%)$ & $3(3.1 \%)$ & 0.95 \\
\hline
\end{tabular}


Abbreviations: TCMR, T cell-mediated rejection; AMR, antibody-mediated rejection; TG, transplant glomerulopathy; IF/TA, interstitial fibrosis/tubular atrophy; AKI, acute kidney

injury; CNI, calcinurin inhibitor; KD, kidney disease.

The frequency of acute TCMR was $34 \%$ in the early biopsies compared to $9 \%$ in late biopsies, a significant difference, $P<0.001$. The median time of biopsy of acute TCMR was 60 days posttransplantation (IQR 12 to 202 days) but with 14 cases (20\%) being diagnosed sporadically at one to 10 years. Acute TCMR tended to be mild, with $76 \%$ being classified as grade I tubulointerstitial disease and $26 \%$ as grade II cellular rejection with vascular involvement.

Seven acute TCMR patients were noncompliant, and 71 were compliant. The two groups showed no significant differences in the histologic scores of inflammation $(P=0.12)$, tubulitis $(P=0.59)$, or vasculitis $(p=0.48)$, and there was no difference in their rates of graft failure (noncompliant one failure, compliant 11 failures, $P=0.17)$.

Active AMR began to be seen in the first year and overlapped with the early first year peak of acute TCMR and AKI (Figure 3). Active AMR was relatively equally distributed between early and late biopsies and occurred at a frequency of just over $8 \%$ of biopsies over a post-transplant period of 10 years.

TG and IF/TA were found mainly in late biopsies or late in the first year post-transplantation. Figure 4 compares the frequency of diagnosis of the chronic conditions of TG, IF/TA, chronic TCMR, and recurrent or de novo KD. The most common diagnoses in the late period were IF/TA at $23.7 \%$ and TG at $19.6 \%$, with a ratio of active AMR to TG of 1:2.4 (42\%).

The 2020 biopsies of previously unbiopsied 2019 patients consisted of the following diagnoses with their median post-transplant times (and IQR): non-specific changes, $n=6,1538$ days (428-3467); AKI, $n=3,150$ days (150-650); Acute TCMR, $n=32,392$ days (270-750); active AMR, $n=15,1825$ days (750-2555); Chronic TCMR, $n=11,1825$ days (750-2190); TG, $n=15,2555$ days (1460-3650); IF/TA, $n=20,2372$ days (836-3293); CNI toxicity, $n=5,548$ days (290-923); recurrent or de novo disease, $n=14,1095$ days (7251460); pyelonephritis, $n=6,730$ days (341-2580); BK nephropathy, $n=3$ (240-750). The 2020 biopsies reflect AKI and acute TCMR complicating transplants performed toward the end of 2019 and chronic conditions that were clinically silent in 2019 .

\section{Allograft failures}

By the end of 2020, graft failure occurred in 117 patients (Table 3). In the early post-transplant period, forty-nine grafts were lost, with the most frequent diagnoses being acute TCMR, $n=11 ; A K I, n=8$; and infarction, $n=7$. After receiving second transplants, two patients with active AMR lost grafts within 7 days because of pre-existing DSA and hyperacute rejection.

Table 3. Graft failures by diagnosis, age, hemodialysis failure, and post-transplant time to graft loss. 


\begin{tabular}{|lllll|}
\hline Diagnosis & $\mathrm{n}(\%)$ & $\mathrm{n}(\%)$ & Patient age & $\begin{array}{l}\text { Transplant } \\
\text { all-cause }\end{array}$ \\
$\mathrm{HD}$ & $8(6.8)$ & $4(4.5)$ & $44(7-50)$ & $16(7-30)$ \\
\hline AKI & $7(6.0)$ & $5(5.7)$ & $40(37-43)$ & $14(7-22)$ \\
\hline Infarction & $11(9.4)$ & $7(8.0)$ & $38(34-50)$ & $120(12-333)$ \\
\hline Acute TCMR & $17(14.5)$ & $16(18.2)$ & $41(33-44)$ & $1460(14-2555)$ \\
\hline Active AMR & $8(6.8)$ & $7(8.0)$ & $41(33-44)$ & $1245(1003-1909)$ \\
\hline Chronic TCMR & $16(13.7)$ & $13(14.8)$ & $40(33-50)$ & $2372(1027-2646)$ \\
\hline TG & $28(23.8)$ & $22(25.0)$ & $41(30-47)$ & $1552(548-3102)$ \\
\hline IF/TA & $3(2.6)$ & $3(3.4)$ & $62(51-56)$ & $910(560-1185)$ \\
\hline CNI toxicity & $11(9.4)$ & $6(6.8)$ & $36(29-47)$ & $810(360-1825)$ \\
\hline Recurrent or de novo KD & $3(2.6)$ & $2(2.3)$ & $52(38-55)$ & $1095(593-1368)$ \\
\hline pyelonephritis & $5(4.3)$ & $3(3.4)$ & $58(57-64)$ & $365(340-740)$ \\
\hline BK virus nephropathy & 117 & $88(75.2)$ & & \\
\hline
\end{tabular}

Values for age and transplant time are for all-cause failure and are expressed as median (interquartile range). Abbreviations: HD, hemodialysis; DWFG, death with functional graft; AKI, acute kidney injury; TCMR, T cell-mediated rejection; AMR, antibody-mediated

rejection; TG, Transplant glomerulopathy; IF/TA, interstitial fibrosis and tubular atrophy;

$\mathrm{CNI}$ calcineurin inhibitor; KD, kidney disease.

The pathology of graft loss because of acute TCMR was complicated. Three of the eleven patients had a vasculitis. One patient had a Banff grade IIA acute TCMR on day six that progressed to a TMA with cortical infarction and HD on day 66 post-transplantation. Another patient had a Banff grade IB acute TCMR at 365 days that advanced to IF/TA grade III and HD by day 1135 . Four of the eleven acute TCMR failures were DWFG.

Graft loss with AKI presented a similar complicated picture. Four of the eight failures were DWFG. One patient had graft biopsies showing AKI on days 90 and 120 and then IF/TA grade III requiring HD at 455 days. Another patient with AKI and grade I IF/TA on day 1095 progressed to IF/TA grade III and HD at 1460 days.

In the late period, sixty-eight patients lost grafts. The most common diagnoses were IF/TA, $\mathrm{n}=28$; $T \mathrm{G}$, $n=16$; $C 4 d+$ active AMR, $n=14$; and recurrent or de novo KD, $n=11$. DWFG was responsible for $24.8 \%$ of graft loss and occurred nearly equally in the early $(n=15)$ and late $(n=14)$ post-transplant periods. The 
attributed cause of 13 cases of DWFG, including four COVID-19 cases, was infection (Table 4). Four patients over 50 years of age had sudden deaths that may have been myocardial.

Table 4. Death with a functional graft by biopsy diagnosis, number of deaths, age, post-transplant time, and causes of death.

\begin{tabular}{|c|c|c|c|c|}
\hline Biopsy diagnosis & $\mathrm{n}$ & $\begin{array}{l}\text { Age } \\
\text { years }\end{array}$ & $\begin{array}{l}\text { Post- } \\
\text { transplant } \\
\text { time days }\end{array}$ & Causes of death \\
\hline AKI & 4 & $\begin{array}{l}41(37- \\
46)\end{array}$ & $15(2-108)$ & Infection (2), COVID-19, unk \\
\hline Infarction & 2 & 26,53 & 7,42 & Infection (2) \\
\hline aTCMR & 4 & $\begin{array}{l}39(33- \\
40)\end{array}$ & $110(9-232)$ & Infection, unk (3) \\
\hline aAMR & 1 & 54 & 22 & Myocardial? \\
\hline cTCMR & 1 & 47 & 730 & Unk \\
\hline TG & 3 & $\begin{array}{l}48(43- \\
58)\end{array}$ & $\begin{array}{l}1460(958- \\
2007)\end{array}$ & COVID-19 (3) \\
\hline IF/TA & 6 & $\begin{array}{l}50(28- \\
53)\end{array}$ & $\begin{array}{l}970(609- \\
1695)\end{array}$ & $\begin{array}{l}\text { COVID-19, PTLPD, infection, myocardial ?, unk } \\
\text { (2) }\end{array}$ \\
\hline $\begin{array}{l}\text { Recurrent/denovo } \\
\text { KD }\end{array}$ & 5 & $\begin{array}{l}38(36- \\
41)\end{array}$ & $\begin{array}{l}420(240- \\
2190)\end{array}$ & $\begin{array}{l}\text { Myeloma, AA amyloidosis, pancreatitis, } \\
\text { myocardial?, unk }\end{array}$ \\
\hline Pyelonephritis & 1 & $\begin{array}{l}52(38- \\
55)\end{array}$ & $\begin{array}{l}1095(593- \\
1368)\end{array}$ & Infection \\
\hline \multirow[t]{2}{*}{$\begin{array}{l}\text { BK virus } \\
\text { nephropathy }\end{array}$} & 2 & $\begin{array}{l}58(57- \\
64)\end{array}$ & $\begin{array}{l}365(340- \\
740)\end{array}$ & Infection, myocardial ? \\
\hline & 29 & & & \\
\hline
\end{tabular}

For more than two entries, values for age and post-transplant time are expressed as median (interquartile range). Abbreviations: HD, hemodialysis; AKI, acute kidney injury; aTCMR, acute T cell-mediated rejection; aAMR, active antibody-mediated rejection; cTCMR, chronic T cell-mediated rejection; TG, Transplant glomerulopathy; IF/TA, interstitial fibrosis and tubular atrophy; CNI calcineurin inhibitor; KD, kidney disease; unk, unknown; PTLD, post-transplant lymphoproliferative disease.

Estimated Iraqi one- and five-year failure rates for all-cause, HD, and death are shown in Table 5 together with the 2000 and 2010 rates for living-donor transplants in the United States (US) reported in the 2017 US Renal Data Service (USRDS) Annual Data Report [19]. The Iraqi data resembles living-donor failure rates in the US in 2000 for both death and HD. It is notable that death and HD failure rates in both Iraqi and the US in 2000 are higher than the lowered rates achieved in the US by 2010 . 
Table 5: One- and five-year living-donor transplant failure rates. Estimated current Iraqi Kurdistan rates (95\% confidence intervals) are compared with reported United States (US) outcomes in 2000 and 2010 [20].

\begin{tabular}{|cllllll|}
\hline \multicolumn{4}{|c|}{ One-year graft failure (\%) } & \multicolumn{3}{l|}{ five-year graft failure (\%) } \\
\hline Site, year & All-cause & HD & Death & All-cause & HD & Death \\
\hline Iraq, 2019 & 9.1 & 6.3 & 2.9 & 23.8 & 17.7 & 7.4 \\
& $(6.5-11.7)$ & $(4.1-8.5)$ & $(1.3-4.5)$ & $(18.7-28.9)$ & $(12.7-22.5)$ & $(4.2-10.6)$ \\
\hline US, 2000 & 7.0 & 5.0 & 2.6 & 22.3 & 15.2 & 10.6 \\
\hline US, 2010 & 3.7 & 2.4 & 1.4 & 15.3 & 9.6 & 7.3 \\
\hline
\end{tabular}

Abbreviation: HD, hemodialysis

The median Iraqi graft survival for all-cause failures was ten years ( $95 \% \mathrm{Cl}: 8$ to 12 years), and the deathcensured median survival was 15 years ( $95 \% \mathrm{Cl}: 11$ to 19 years). The length of the post-transplant period significantly correlated with the severity of IF/TA ( $R s=0.770, P<0.001)$ and TG (Rs=0.464, $P<0.001)$.

Logistic regression (Table 6) showed that IF/TA and C4d positive IF staining significantly predicted HD but that acute TCMR and AKI did not. DWFG was not significantly related to sex, donor source, IF/TA, TG, C4d staining, AKI, or acute TCMR.

Table 6. Logistic regression models for hemodialysis graft failure and death with a functional graft (DWFG). 


\begin{tabular}{|c|c|c|c|}
\hline \multicolumn{4}{|c|}{ Hemodialysis initial model } \\
\hline Variable & Odds ratio & $P$-value & $95 \% \mathrm{Cl}$ \\
\hline Age & 1.014 & 0.25 & 0.991 to 1.037 \\
\hline Sex & 0.484 & 0.04 & 0.242 to 0.967 \\
\hline Donor source & 1.450 & 0.38 & 0.635 to 3.312 \\
\hline Acute TCMR & 0.413 & 0.08 & 0.152 to 1.123 \\
\hline AKI & 0.701 & 0.47 & 0.270 to 1.821 \\
\hline $\mathrm{C} 4 \mathrm{~d}+$ & 2.264 & 0.04 & 1.044 to 6.576 \\
\hline IF/TA & 1.935 & 0.000 & 1.375 to 2.719 \\
\hline TG & 1.038 & 0.83 & 0.731 to 1.476 \\
\hline \multicolumn{4}{|c|}{ Hemodialysis final model } \\
\hline Sex & 0.647 & 0.16 & 0.355 to 1.179 \\
\hline $\mathrm{C} 4 \mathrm{~d}+$ & 3.427 & 0.01 & 1.325 to 8.865 \\
\hline IF/TA & 2.957 & 0.000 & 1.734 to 2.927 \\
\hline \multicolumn{4}{|c|}{ DWFG initial model } \\
\hline Age & 1.018 & 0.24 & 0.988 to 1.049 \\
\hline Sex & 0.582 & 0.25 & 0.233 to 1.453 \\
\hline Donor source & 0.632 & 0.48 & 0.178 to 2.246 \\
\hline Acute TCMR & 0.492 & 0.27 & 0.138 to 1.754 \\
\hline AKI & 1.339 & 0.60 & 0.453 to 3.962 \\
\hline $\mathrm{C} 4 \mathrm{~d}+$ & 0.245 & 0.20 & 0.029 to 2.090 \\
\hline IF/TA & 1.022 & 0.93 & 0.639 to 1.633 \\
\hline TG & 1.112 & 0.68 & 0.672 to 1.843 \\
\hline \multicolumn{4}{|c|}{ DWFG final model } \\
\hline C4d+ & 0.338 & 0.30 & 0.044 to 2.586 \\
\hline
\end{tabular}

Abbreviations: TCMR, T cell mediated rejection; AKI, acute kidney injury; IF/TA, interstitial fibrosis and tubular atrophy; TG, transplant glomerulopathy. 


\section{Discussion}

The clinical characteristics of our recipients are similar to previous Iraqi studies with transplanted kidneys all coming from living donors [4]. Despite the religious fatwa of 1986 (the Amman declaration) that permits the retrieval and transplantation of deceased donor organs, the numbers of such transplants in the Middle and Near East, while increasing, remain limited $[2,5,14]$.

The universal use of live donors should lessen the promoting effect that prolonged cold ischemia time has on AKI and acute TCMR $[15,16]$. Nevertheless, acute TCMR at $23 \%$ of all biopsies was our most common cause of graft dysfunction. As in Western practices, acute TCMR was generally mild and well managed [17] and was the attributed cause of just $8.5 \%$ of graft loss. Post-transplant AKI was also usually mild. While AKI and infarction resulted in $12.7 \%$ of graft loss, nearly half of that loss was caused by infarction complicating vascular anastomoses. DWFG comprised one-third of the failures associated with acute TCMR and half of the failures associated with AKI.

The all-cause graft loss among 2019 transplant patients followed for an average of 19 months was $13.4 \%$, with $24.8 \%$ of the loss being DWFG. Infections, either sepsis or pneumonia, were the most frequent causes of DWFG. The COVID-19 pandemic reached the Kurdish region in March of 2020. In the 2020 follow-up, COVID-19 caused four patient deaths, representing a $2.9 \%$ death rate among patients positive for COVID-19 by molecular testing, a death rate similar to the $3.3 \%$ among the COVID-19 positive general population [18]. We concluded that COVID-19 did not significantly influence our transplant survival.

The Iraqi one- and five-year transplant failure rates resembled those of US recipients of living-donor kidneys reported by the USRDS for the year 2000 [19]. While Iraqis did not have an increased risk of transplant failure compared to the US in 2000 , the Iraqi failure rates were much higher than those of the US in 2010. The substantial decrease in US living-donor failure rates from 2000 to 2010 was a successful change that might be possible in Iraq, but the factors underlying graft loss in Iraq must be better understood.

Iraqi patients should ostensibly be at low risk for graft failure. With only $17.6 \%$ being more than 50 years old and $6.6 \%$ diabetic, our regional transplant patients are quite different from those on dialysis, where $53 \%$ are over 50 years old, and $23 \%$ are diabetic $[20,21]$. Preemptive transplantation is used for approximately $15 \%$ of Iraqi patients compared to more than $30 \%$ of patients receiving living-donor grafts in the US. Prolonged dialysis before transplantation may have a detrimental effect on graft survival, and it is suggested that preemptive transplantation may improve outcomes [22, 23].

The adverse effect of dialysis on graft survival is reported from the US, where dialysis is likely to be optimal, and dialysis centers are regularly monitored for compliance with established standards of practice [24]. Iraqi transplant candidates are virtually never treated by prolonged dialysis, but the adequacy of the dialysis they receive is uniformly less than adequate. Because of costs and the difficulty of maintaining supplies, more than $80 \%$ of Iraqi patients are dialyzed just twice weekly. Private dialysis facilities are being established to supplement public dialysis, but the value is questionable. Prolonged 
private dialysis in preparation for transplantation will add considerably to costs and will be an economic barrier for many patients.

The estimated median death-censored survival of 15 years is encouraging. The longer patient survival comes with its own contribution to graft loss, and we see the same shift toward chronic and antibodymediated transplant disorders that has occurred in developed countries [6, 7]. Parajuli et al. [8], at the University of Wisconsin transplant service, retrospectively examined biopsies from 329 patients that developed graft failure over the years, 2006-2016. They had a highly sensitized population, and active AMR caused $32 \%$ of graft failure. TG at $17 \%$ and IF/TA at $13 \%$ followed active AMR.

Naesens et al. [25] examined the transplant biopsies of 1,197 patients from the transplant service of the University Hospital of Leuven, Belgium. The donors were $99 \%$ deceased, and $33 \%$ of procedures were repeated transplants. After the second year post-transplantation, IF/TA, TG, and late TCMR were the most common causes of graft failure, and the severity of IF/TA with any diagnosis correlated strongly with graft loss. Like Parajuli et al. [8], the Leuven study found an increased frequency of AMR, and AMR significantly lowered graft survival [25].

Our Iraqi patients have completely different characteristics than those of the Leuven or Wisconsin transplant services. Yet, we see the same influence of AMR, TG, and IF/TA on graft survival. De novo active AMR was associated with more than $8 \%$ of our graft dysfunction in early and late post-transplant periods, and in the late post-transplant period, active AMR was $42 \%$ as frequent as TG. This proportion of active AMR to TG is similar to the $53 \%$ found one year after engraftment in Leuven, with the ratio possibly reflecting the comparative risk of TG as a non-complement binding DSA-mediated disease [25, 26].

Because TG is a frequent cause of progressive late graft dysfunction, its management is an important concern for nephrologists $[9,27,28]$. While the reduction in proteinuria by angiotensin II blockade is the usual treatment for TG, the recognition that TG may be an alloimmune disease suggests that immunosuppression, including the use of rituximab, might be effective $[12,28,29]$. Other proposed factors in TG pathogenesis are NK cell activity and a low-grade TMA [28, 29, 30]. As the methods for investigating these varying mechanisms evolve, the diagnosis and the treatment of TG will undoubtedly change.

The diagnosis of IF/TA presents uncertainties equal to TG. IF/TA is the late stage of different pathologies, and the cause is almost by definition obscure [31]. In two of our cases, IF/TA was preceded by AKI, a relationship recently recognized by Gosset et al. [32]. AKI carries an increased risk of later CKD, and we have documented the progression of AKI to chronicity in Iraqi community patients and now in transplants $[33,34,35]$. There is no currently recommended treatment for idiopathic IF/TA, but the recognition of and intervention in causal events might moderate progression in some cases.

This study has the limitation of estimating complex outcomes over a two-year observation period. In our situation, we believed that a short period of data collection was the best method for ensuring accuracy. Centralized record-keeping does not exist in Iraqi or in most low-resource countries [20,36]. When 
scheduled appointments have not been met, the evaluation of clinical status depends upon mobile telephone calls to patients or their families. By appointment records or mobile calls, we were able to achieve a $95 \%$ determination rate and are reasonably confident in asserting that, for first-time recipients from living-donors, kidney transplant survival in Iraq can approach outcomes in the developed world.

In the foreseeable future, dialysis in most developing countries will remain limited, and transplant-related ESRD will grow. In low-resource countries, repeat transplantation is likely to remain the principal option for further long-term survival. For properly managed patients, the outcomes for second transplants can be as good as those for primary transplants [22]. This success, of course, requires patient selection based upon donor-recipient compatibility [37, 38]. It may also depend upon adequate pretransplant dialysis.

\section{Conclusions}

Difficult to explain DWFG accounted for one-fourth of Iraqi graft failures. All grafts were from living donors, with one- and five-year death censored survival rates of $93.7 \%$ and $82.3 \%$. These rates are only moderately lower than those reported from the US, and we estimated an encouraging 15-year deathcensured median graft survival. Improvement in outcomes should be possible but will require the effective management of chronic transplant disorders and a better understanding of the reasons for DWFG.

\section{Declarations}

\section{Acknowledgments}

Not applicable

\section{Funding}

There was no funding for this research.

\section{Competing interests}

None to declare.

\section{Availability of data and materials}

Compiled data and calculations are stored in Excel files in the Shorsh University Hospital Pathology Department and will be made available upon request to the corresponding author.

\section{Authors contributions}

Study design and concepts was the responsibility of AAA, SEA, KHA, and MDH. Data collection and analysis was performed by AAA, SEA, DAS, ZSMS, KHA, and MDH. AAA prepared the first draft of the manuscript. MDH coordinated manuscript revisions that were read and approved by all authors. 


\section{Ethics approval}

This study was approved by the ethical committee of the faculty of medical sciences /University of Sulaimani (\#11N/29). The research was conducted according to the Helsinki Accords. It was a review of existing medical records including routine follow-up telephone calls to evaluate patient status and compliance with scheduled clinic visits. No additional patient intervention was undertaken. The ethics committee of the University of Sulaimani determined that all patient contact was standard-of-practice for kidney care in Iraqi Kurdistan. As a review of existing medical records, the research did not require informed consent. Iraqi law prohibits compensation for donating organs. The law requires a donor interview with a regional ethics committee and a signed statement that the donation is voluntary. These statements are retained as institutional records.

\section{Consent for publication}

Not applicable. The research described results in aggregate and without personal identifiers.

\section{References}

1. Couser WG, Remuzzi G, Mendis S, Tonelli M. The contribution of chronic kidney disease to the global burden of major noncommunicable diseases. Kidney Int. 2011; 80:1258-1270.

2. White SL, Chandban SJ, Jan S, Chapman JR, Cass A. How can we achieve global equity in provision of renal replacement therapy. Bull World Health Organ. 2008;86:229-237.

3. Garcia Garcia G, Harden P, Chapman J, for the World Kidney Day Steering Committee 2012. Am J Nephrol. 2012;35:259-264.

4. Ali A, Al-Saedi A, Al-Mudhaffer A, Al-Taee K. Five years renal transplantation data: Single-center experience from Iraq. Saudi J Kidney Dis Transpl. 2016;27:341-347.

5. Taheri D, Talebi A, Salem V, Fesharakizadeh M, Dolatkhah S, Mahzouni P. An Iranian experience on renal allograft diseases. J Res Med Sci. 2011;16:1572-1577.

6. Hart A, Smith JM, Skeans MA, Gustafson SK, Wilk AR, Castro S, Robinson A, Wainright JL, Snyder JJ, Kasiske BL, Israni AK. OPTN/SRTR 2017 Annual Data Report: Kidney. Am J Transplant. 2019 Feb: 19 Suppl 2: 19-123.

7. El-Zoghby Z, Stegall M, Lager D, Kremers W, Amer H, Gloor J et al. Identifying Specific Causes of Kidney Allograft Loss. Am J Transplant. 2009;9:527-535.

8. Parajuli S, Aziz F, Garg N, Panzer S, Joachim E, Muth B et al. Histopathological characteristics and causes of kidney graft failure in the current era of immunosuppression. World $\mathrm{J}$ Transplant. 2019;9:123-133.

9. Sellares J, de Freitas DG, Mengel M, Reeve J, Einecke G, Sis B, Hidalgo LG, Famulski K, Matas A, Halloran PF. Understanding the causes of kidney transplant failure: The dominant role of antibodymediated rejection and nonadherence. Am J Transplant. 2012;12:388-399. 
10. Colvin RB. Antibody-mediated renal allograft rejection: diagnosis and pathogenesis. Review. J Am Soc Nephrol. 2007; 18:1046-1056.

11. Haas M, Loupy A, Lefaucheur C, Roufosse C, Glotz D, Seron D et al. The Banff 2017 Kidney Meeting Report: Revised diagnostic criteria for chronic active T cell-mediated rejection, antibody-mediated rejection, and prospects for integrative endpoints for next-generation clinical trials. Am J Transplant. 2018;18:293-307.

12. Williams W, Taheri D, Tolkoff-Rubin N, Colvin R. Clinical role of the renal transplant biopsy. Nat Rev Nephrol. 2012;8:110-121.

13. Ali A, Al-Malla S, Al-Saedi A. Renal transplantation in Iraq: History, Current Status and Future Perspectives. Iraqi New Medical Journal. 2016 (1):10-14.

14. Ali A, Elzein H. The Iraqi Renal Transplant Registry (IRTR): The first step toward an Iraqi renal data system. Iraqi New Medical Journal. 2018 (4):86-90.

15. Postalcioglu M, Kaze AD. Byun BC, Siedlecki A, Tullius SG, Milford EL, Paik JM, Abdi R. Association of cold ischemia time with acute transplant rejection. Transplantation. 2018;102:1188-1194.

16. Debout A, Foucher Y, Trebern-Launay K, Legendre C, Kreis H, Mourad G, Garrigue V, Morelon E, Buron F, Rostaing L, Kamar N, Kessler M, Ladriere M, Poignas A, Blidi A, Soulillou J-P, Giral M, Dantan E. Each additional hour of cold ischemia time increases the risk for graft failure and mortality following renal transplantation. Kidney Int. 2015;87:343-349.

17. Halloran PF, Reeve JP, Pereira AB, Hidalgo LG, Famulski KS. Antibody-mediated rejection, T cellmediated rejection, and the injury-repair response: new insights from the Genome Canada studies of kidney transplant biopsies. Kidney Int. 2014;85:258-264.

18. Department of Media Information. Kurdistan Region-Iraq. Ministry of Health. Situation update. COVID-19. www.gov.krd/coronovirus-en/situation update (accessed January 27, 2021).

19. United States Renal Data System. 2017 USRDS Annual Data Report: Chapter 6: Transplantation. Am J Kidney Dis. 2018; 71 (Suppl 1): S351-S382.

20. Ali AA, Sharif DA, Almukhtar SE, Abd KH, Saleem ZSM, Hughson MD. Incidence of glomerulonephritis and non-diabetic end-stage renal disease in a developing middle-east region near armed conflict. BMC Nephrol. 2018;19:257.

21. Sharif DA, Awn AH, Murad KM, Meran IMA. Demographic and characteristic distribution of end-stage renal failure in Sulaimani Governate, Kurdistan Region, Iraq. Int J Med Res Prof. 2017;3:155-158.

22. Wang JH, Skeans MA, Israni AK. Current status of kidney transplant outcomes: Dying to survive. Adv Chronic Kidney Dis. 2016; 23:281-286.

23. Meier-Kriesche HU, Port FK, Ojo AO, Rudich SM, Hanson JA, Cibrik DM, LeichtmanAB, Kaplan B. Effect of waiting time on transplant outcome. Kidney Int. 2000;58:1311-1317.

24. Conditions for coverage of end-stage renal disease facilities; final rule published in the Federal Register on April 15, 2008. The Survey and Certification Program. Centers for Medicare and Medicaid Services. www.cms.gov/Medicare/Provider-Enrollment-andCerification/GuidanceforLawsandRegulations/Dialysis (accessed January 29,2021). 
25. Naesens M, Kuypers DRJ, De Vusser K, Evenepoel P, Claes K, Bammens B, Meijers B, Sprangers B, Pirenne J, Monbaliu D, Jochmans I, Lerut E. The histology of kidney transplant failure: a long-term follow-up study. Transplantation. 2014;98:427-435.

26. Zhang R. Donor-specific antibodies in kidney transplant recipients. Clin J Am Soc Nephrol. 2018; 13:182-192.

27. Cosio FG, Gloor JM, Sethi S, Stegall MD. Transplant glomerulopathy. Amer J Transplant. 2008;8:492496.

28. Rostaing L, Guilbeau-Frugier C, Fort M, Mekhlati L, Kamar N. Treatment of symptomatic transplant glomerulopathy with rituximab. Transpl Int. 2009;22:906-913.

29. Filipono EJ, McCue PA, Farber JL. Transplant glomerulopathy. Mod Pathol. 2018; 31:235-252.

30. Loupy A, LeFaucheur C. Antibody-mediated rejection of solid-organ allografts. N Engl J Med. 2018;379:1150-1160.

31. Mengel M. Deconstructing interstitial fibrosis and tubular atrophy: a step toward precision medicine in renal transplantation. Kidney Int. 2017;92:553-555.

32. Gosset C, Viglietti D, Rabant M, Verine J, Aubert O, Glotz D, Legendre C, Taupin JL, Duong Van Huyen JP, Loupy A, LeFaucheur C. Circulating donor-specific anti-HLA antibodies are a major factor in premature and accelerated allograft fibrosis. Kidney Int. 2017;92:729-742.

33. Ali AA, Almukhtar SE, Sharif DA, Saleem ZSM, Muhealdeen DN, Hughson MD. Effects of bodybuilding supplements on the kidney: A population-based incidence study of biopsy pathology and clinical characteristics among middle eastern men. BMC Nephrology. 2020; 21:164.

34. Leither MD, Murphy DP, Bicknese L, Reule S, Vock DM, Ishani A, Foley RN, Drawz PE. The impact of outpatient kidney injury on mortality and chronic kidney disease: a retrospective cohort study. Nephrol Dial Transplant. 2019;34:493-501.

35. Sawhney S, Marks A, Fluck N, Levin A, Prescott G, Black C. Intermediate and long-term outcomes of acute kidney injury of survivors of acute kidney injury episodes. Am J Kidney Dis. 2016;69:18-28.

36. Anand S, Bitton A, Gaziano T. The gap between estimated incidence of end-stage renal disease and the use of therapy. Plos One. 2013; 8:e72860.

37. Morris AB, Sullivan HC, Krummey SM, Gebel HM, Bray RA. Out with the old, in with the new: Virtual versus physical cross-matching in the modern era. HLA. 2019;94:41-481.

38. Alzahrani M, Qahtani Z, Harbi H, Kebasi S, Essa O, Al Attas R. Virtual cross-match: reality of perception. Transplant proc. 2019;51:488-491.

\section{Tables}

Table 1: Clinical characteristic of recipients 


\begin{tabular}{|l|l|}
\hline Characteristic & value \\
\hline Median age, years & 39 (IQR 28-48) \\
\hline > 50 years old & $19.5 \%$ \\
\hline Males & $77.6 \%$ \\
\hline Diabetes & $6.6 \%$ \\
\hline Living donor & $100 \%$ \\
\hline Related donor & $16.2 \%$ \\
\hline Serum creatinine at biopsy (mg/dl) & 2.0 (IQR 1.6-2.6) \\
\hline Previous transplant & $5.5 \%$ \\
\hline Pretransplant DSA positive & $3.7 \%$ \\
\hline Noncompliant & $6.6 \%$ \\
\hline Time of biopsy post-transplantation, days & 150, range 1 to 6570 \\
& $(\mathrm{IQR} 30-940)$ \\
\hline Maintenance immunosuppression & \\
\hline CNI (tacrolimus/cyclosporine), MMF, steroid & $62.1 \%$ \\
\hline CNI (tacrolimus/cyclosporine), steroid & $37.9 \%$ \\
\hline Indication for biopsy: & \\
\hline Primary nonfunction & $14.1 \%$ \\
\hline Deterioration of graft function & $77.9 \%$ \\
\hline Proteinuria & $7.9 \%$ \\
\hline
\end{tabular}

Abbreviations: Continuous variables of age and serum creatinine and time of biopsy are expressed as median and interquartile range. IQR, interquartile range. CNI: calcineurin inhibitor (tacrolimus/cyclosporine); MMF: mycophenolate mofetil; DSA, Donor-specific antibody.

Table 2: Pathological diagnoses in early and late transplant biopsies.

\begin{tabular}{|c|c|c|c|}
\hline $\begin{array}{l}\text { Pathological } \\
\text { lesions }\end{array}$ & $\begin{array}{l}\text { Early biopsies } \leq \text { one year } \\
(\mathrm{n}=204)\end{array}$ & $\begin{array}{l}\text { Late biopsies }>\text { one year } \\
(n=97)\end{array}$ & $\begin{array}{l}\text { Early vs } \\
\text { Late } \\
P \text {-value }\end{array}$ \\
\hline AKI & $56(27.5 \%)$ & $2 \quad(2.1 \%)$ & $<0.001$ \\
\hline Infarction & $8 \quad(3.9 \%)$ & $1 \quad(1.0 \%)$ & 0.34 \\
\hline Acute TCMR & $69(33.8 \%)$ & $9 \quad(9.3 \%)$ & $<0.001$ \\
\hline AMR C4d+ & $17(8.3 \%)$ & $9 \quad(9.3 \%)$ & 0.98 \\
\hline Chronic TCMR & $5 \quad(2.5 \%)$ & $\begin{array}{ll}6 & (6.2 \%) \\
\end{array}$ & 0.22 \\
\hline TG & $4 \quad(2.0 \%)$ & $19(19.6 \%)$ & $<0.001$ \\
\hline $\mathrm{IF} / \mathrm{TA}$ & $13(6.4 \%)$ & $23(23.7 \%)$ & $<0.001$ \\
\hline CNI toxicity & 12 (5.9\%) & $7 \quad(9.5 \%)$ & 0.87 \\
\hline $\begin{array}{l}\text { Recurrent or de } \\
\text { novo KD }\end{array}$ & $8 \quad(3.9 \%)$ & $17(17.5 \%)$ & $<0.001$ \\
\hline $\begin{array}{l}\text { Acute } \\
\text { pyelonephritis }\end{array}$ & $7 \quad(3.4 \%)$ & 1 (1.0\%) & 0.43 \\
\hline $\begin{array}{l}\text { BK virus } \\
\text { nephropathy }\end{array}$ & $5 \quad(2.5 \%)$ & $3(3.1 \%)$ & 0.95 \\
\hline
\end{tabular}

Abbreviations: TCMR, T cell-mediated rejection; AMR, antibody-mediated rejection; TG, transplant glomerulopathy; IF/TA, interstitial fibrosis/tubular atrophy; AKI, acute kidney injury; CNI, calcinurin inhibitor; KD, kidney disease. 
Table 3. Graft failures by diagnosis, age, hemodialysis failure, and post-transplant time to graft loss.

\begin{tabular}{|l|c|c|c|c|}
\hline Diagnosis & $\begin{array}{c}\mathrm{n}(\%) \\
\text { all-cause }\end{array}$ & $\begin{array}{c}\mathrm{n}(\%) \\
\mathrm{HD}\end{array}$ & $\begin{array}{c}\text { Patient age } \\
\text { years }\end{array}$ & $\begin{array}{c}\text { Transplant } \\
\text { time days }\end{array}$ \\
\hline AKI & $8(6.8)$ & $4(4.5)$ & $44(7-50)$ & $16(7-30)$ \\
\hline Infarction & $7(6.0)$ & $5(5.7)$ & $40(37-43)$ & $14(7-22)$ \\
\hline Acute TCMR & $11(9.4)$ & $7(8.0)$ & $38(34-50)$ & $120(12-333)$ \\
\hline Active AMR & $17(14.5)$ & $16(18.2)$ & $41(33-44)$ & $1460(14-2555)$ \\
\hline Chronic TCMR & $8(6.8)$ & $7(8.0)$ & $41(33-44)$ & $1245(1003-1909)$ \\
\hline TG & $16(13.7)$ & $13(14.8)$ & $40(33-50)$ & $2372(1027-2646)$ \\
\hline IF/TA & $28(23.8)$ & $22(25.0)$ & $41(30-47)$ & $1552(548-3102)$ \\
\hline CNI toxicity & $3(2.6)$ & $3(3.4)$ & $62(51-56)$ & $910(560-1185)$ \\
\hline Recurrent or de novo KD & $11(9.4)$ & $6(6.8)$ & $36(29-47)$ & $810(360-1825)$ \\
\hline pyelonephritis & $3(2.6)$ & $2(2.3)$ & $52(38-55)$ & $1095(593-1368)$ \\
\hline BK virus nephropathy & $5(4.3)$ & $3(3.4)$ & $58(57-64)$ & $365(340-740)$ \\
\hline & 117 & $88(75.2)$ & & \\
\hline
\end{tabular}

Values for age and transplant time are for all-cause failure and are expressed as median (interquartile range). Abbreviations: $\mathrm{HD}$, hemodialysis; DWFG, death with functional graft; AKI, acute kidney injury; TCMR, T cell-mediated rejection; AMR, antibody-mediated rejection; TG, Transplant glomerulopathy; IF/TA, interstitial fibrosis and tubular atrophy; CNI calcineurin inhibitor; KD, kidney disease.

Table 4. Death with a functional graft by biopsy diagnosis, number of deaths, age, posttransplant time, and causes of death.

\begin{tabular}{|l|c|c|c|l|}
\hline Biopsy diagnosis & $\mathrm{n}$ & $\begin{array}{c}\text { Age } \\
\text { years }\end{array}$ & $\begin{array}{c}\text { Post- } \\
\text { transplant } \\
\text { time days }\end{array}$ & \\
\hline AKI & 4 & $\begin{array}{c}41(37- \\
46)\end{array}$ & $15(2-108)$ & Infection (2), COVID-19, unk \\
\hline Infarction & 2 & 26,53 & 7,42 & Infection (2) \\
\hline aTCMR & 4 & $\begin{array}{c}39(33- \\
40)\end{array}$ & $\begin{array}{l}110(9-232) \\
\text { Infection, unk (3) }\end{array}$ & \\
\hline aAMR & 1 & 54 & 22 & Myocardial? \\
\hline cTCMR & 1 & 47 & 730 & Unk \\
\hline TG & 3 & $\begin{array}{c}48(43- \\
58)\end{array}$ & $\begin{array}{c}1460(958- \\
2007)\end{array}$ & COVID-19 (3) \\
\hline IF/TA & 6 & $\begin{array}{c}50(28- \\
53)\end{array}$ & $\begin{array}{c}970(609- \\
1695)\end{array}$ & $\begin{array}{l}\text { COVID-19, PTLPD, infection, myocardial } \\
\text { ?, unk (2) }\end{array}$ \\
\hline Recurrent/denovo & 5 & $\begin{array}{c}38(36- \\
\text { KD }\end{array}$ & $\begin{array}{c}420(240- \\
2190)\end{array}$ & $\begin{array}{l}\text { Myeloma, AA amyloidosis, pancreatitis, } \\
\text { myocardial?, unk }\end{array}$ \\
\hline Pyelonephritis & 1 & $\begin{array}{c}52(38- \\
55)\end{array}$ & $\begin{array}{c}1095(593- \\
1368)\end{array}$ & Infection \\
\hline BK virus & & $58(57-$ & $365(340-$ & Infection, myocardial ? \\
nephropathy & 2 & $64)$ & $740)$ & \\
\hline & 29 & & & \\
\hline
\end{tabular}

For more than two entries, values for age and post-transplant time are expressed as median (interquartile range). Abbreviations: HD, hemodialysis; AKI, acute kidney injury; aTCMR, acute T cell-mediated rejection; aAMR, active antibody-mediated rejection; cTCMR, chronic T cell-mediated rejection; TG, Transplant glomerulopathy; IF/TA, 
interstitial fibrosis and tubular atrophy; CNI calcineurin inhibitor; KD, kidney disease; unk, unknown; PTLD, post-transplant lymphoproliferative disease.

Table 5: One- and five-year living-donor transplant failure rates. Estimated current Iraqi Kurdistan

rates (95\% confidence intervals) are compared with reported United States (US) outcomes in 2000

and 2010 [20].

\begin{tabular}{|l|c|c|c|c|c|c|}
\hline & \multicolumn{3}{|c|}{ One-year graft failure (\%) } & \multicolumn{3}{c|}{ five-year graft failure (\%) } \\
\hline Site, year & All-cause & HD & Death & All-cause & HD & Death \\
\hline Iraq, 2019 & 9.1 & 6.3 & 2.9 & 23.8 & 17.7 & 7.4 \\
& $(6.5-11.7)$ & $(4.1-8.5)$ & $(1.3-4.5)$ & $(18.7-28.9)$ & $(12.7-22.5)$ & $(4.2-10.6)$ \\
\hline US, 2000 & 7.0 & 5.0 & 2.6 & 22.3 & 15.2 & 10.6 \\
\hline US, 2010 & 3.7 & 2.4 & 1.4 & 15.3 & 9.6 & 7.3 \\
\hline
\end{tabular}

Abbreviation: HD, hemodialysis

Table 6. Logistic regression models for hemodialysis graft failure and death with a functional graft (DWFG).

\begin{tabular}{|l|l|l|l|}
\hline \multicolumn{4}{|c|}{ Hemodialysis initial model } \\
\hline Variable & Odds ratio & $P$-value & $95 \%$ CI \\
\hline Age & 1.014 & 0.25 & 0.991 to 1.037 \\
\hline Sex & 0.484 & 0.04 & 0.242 to 0.967 \\
\hline Donor source & 1.450 & 0.38 & 0.635 to 3.312 \\
\hline Acute TCMR & 0.413 & 0.08 & 0.152 to 1.123 \\
\hline AKI & 0.701 & 0.47 & 0.270 to 1.821 \\
\hline C4d+ & 2.264 & 0.04 & 1.044 to 6.576 \\
\hline IF/TA & 1.935 & 0.000 & 1.375 to 2.719 \\
\hline TG & 1.038 & 0.83 & 0.731 to 1.476 \\
\hline \multicolumn{4}{|c|}{ Hemodialysis final model } \\
\hline Sex & 0.647 & 0.16 & 0.355 to 1.179 \\
\hline C4d+ & 3.427 & 0.01 & 1.325 to 8.865 \\
\hline IF/TA & 2.957 & 0.000 & 1.734 to 2.927 \\
\hline \multicolumn{4}{|c|}{ DWFG initial model } \\
\hline Age & 1.018 & 0.24 & 0.988 to 1.049 \\
\hline Sex & 0.582 & 0.25 & 0.233 to 1.453 \\
\hline Donor source & 0.632 & 0.48 & 0.178 to 2.246 \\
\hline Acute TCMR & 0.492 & 0.27 & 0.138 to 1.754 \\
\hline AKI & 1.339 & 0.60 & 0.453 to 3.962 \\
\hline C4d+ & 0.245 & 0.20 & 0.029 to 2.090 \\
\hline IF/TA & 1.022 & 0.93 & 0.639 to 1.633 \\
\hline TG & 1.112 & 0.68 & 0.672 to 1.843 \\
\hline \multicolumn{5}{|c|}{ DWFG final model } \\
\hline C4d+ & 0.338 & 0.30 & 0.044 to 2.586 \\
\hline
\end{tabular}


Abbreviations: TCMR, T cell mediated rejection; AKI, acute kidney injury; IF/TA, interstitial fibrosis and tubular atrophy; TG, transplant glomerulopathy.

\section{Figures}

Figure 1. Flowchart showing the patient population, the number of biopsies, and the identification of graft failures.

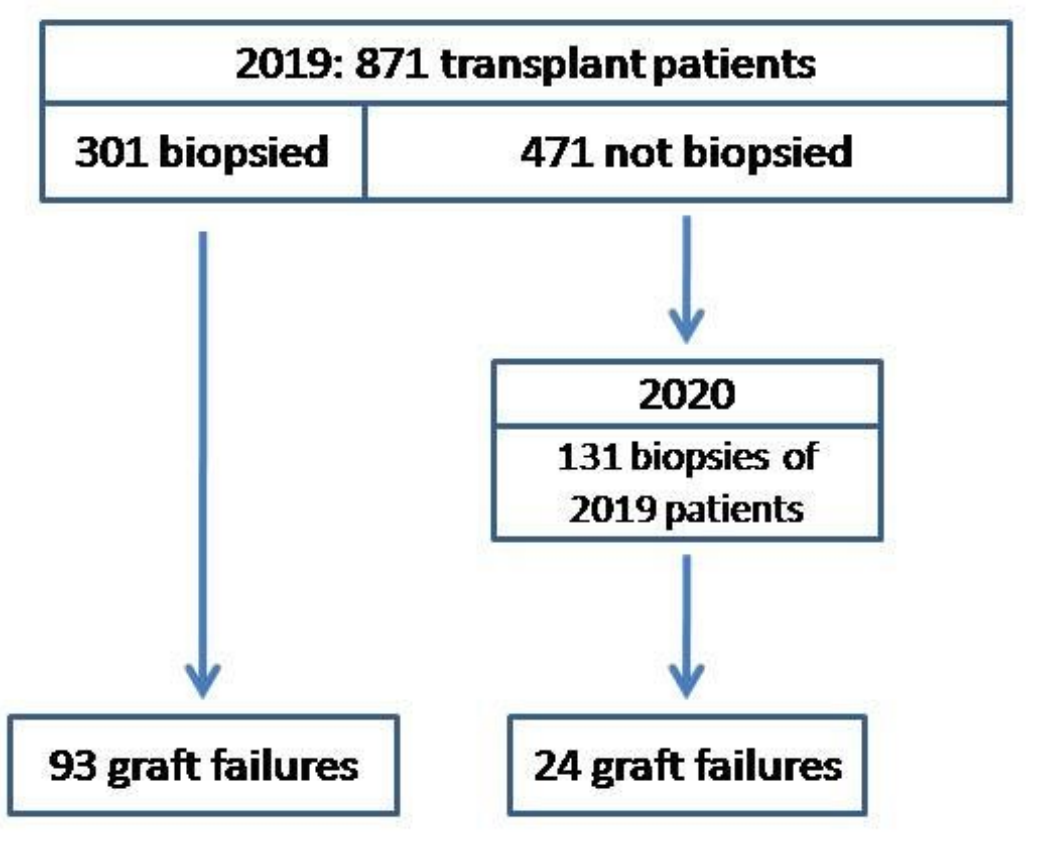

Note: No graft failures by death or hemodialysis were identified in patients who were not biopsied

Figure 1

Figure 1 provides a flowchart of the patient follow-up with the number of biopsies and graft failures. 
Figure 2. Distribution of diagnoses in descending order of frequency.

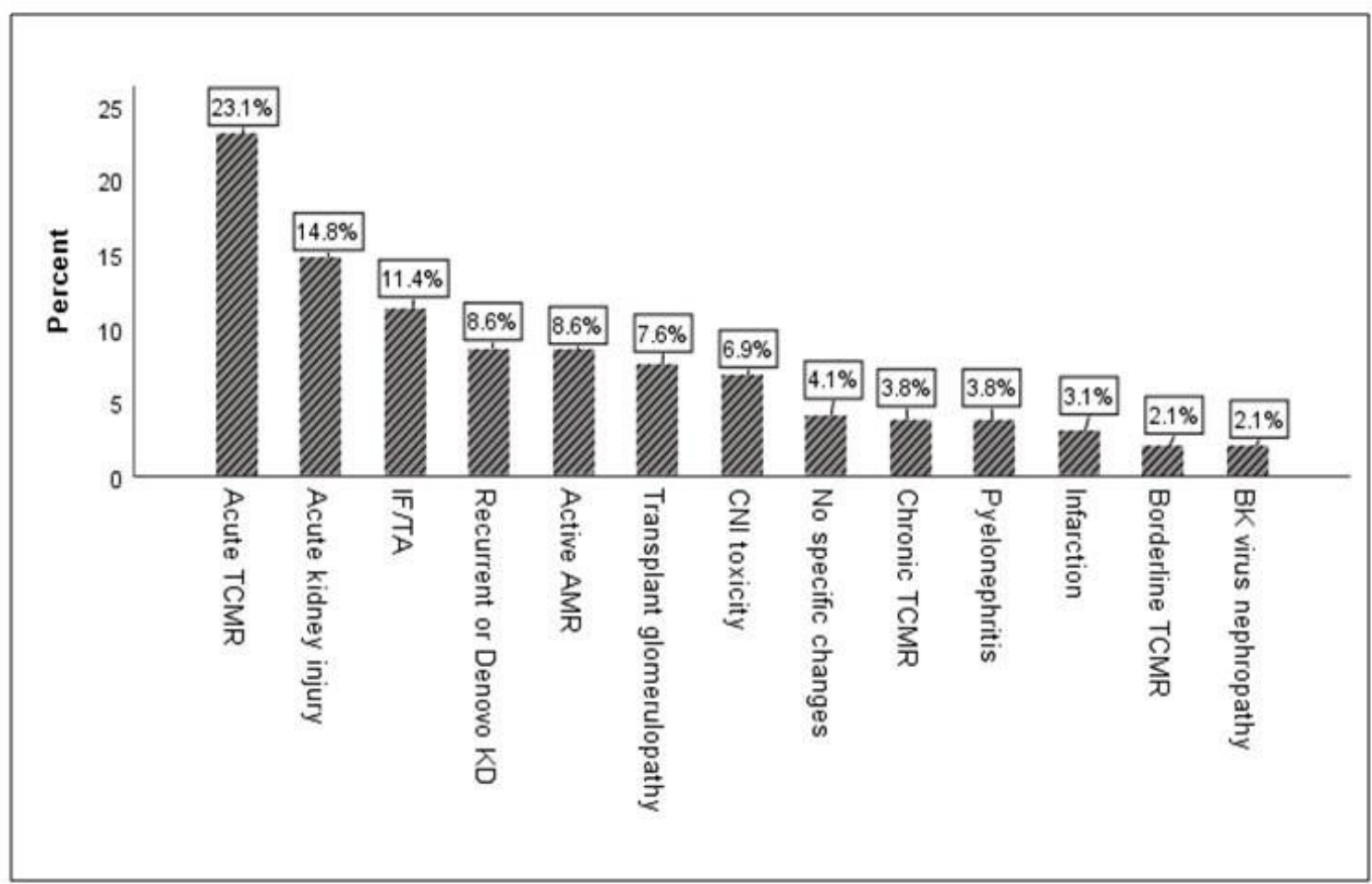

Abbreviations: TCMR, T cell-mediated rejection; IF/TA, interstitial fibrosis and tubular atrophy; KD, kidney disease; AMR, antibody-mediated rejection; $\mathrm{CNI}$, calcineurin inhibitor.

Figure 2

Figure 2 shows the distribution of 2019 diagnoses. The most common diagnosis was acute TCMR at $23.1 \%$, followed by AKI at $14.8 \%$, IF/TA at $11.4 \%$, recurrent or de novo $\mathrm{KD}$ at $8.6 \%$, TG at $7.6 \%$, and CNI toxicity at $6.9 \%$. Other specific diagnoses occurred at a frequency of less than $4 \%$. Active C4d+ AMR was diagnosed in $8.6 \%$ of patients. 
Figure 3. Distribution of acute transplant changes over time.

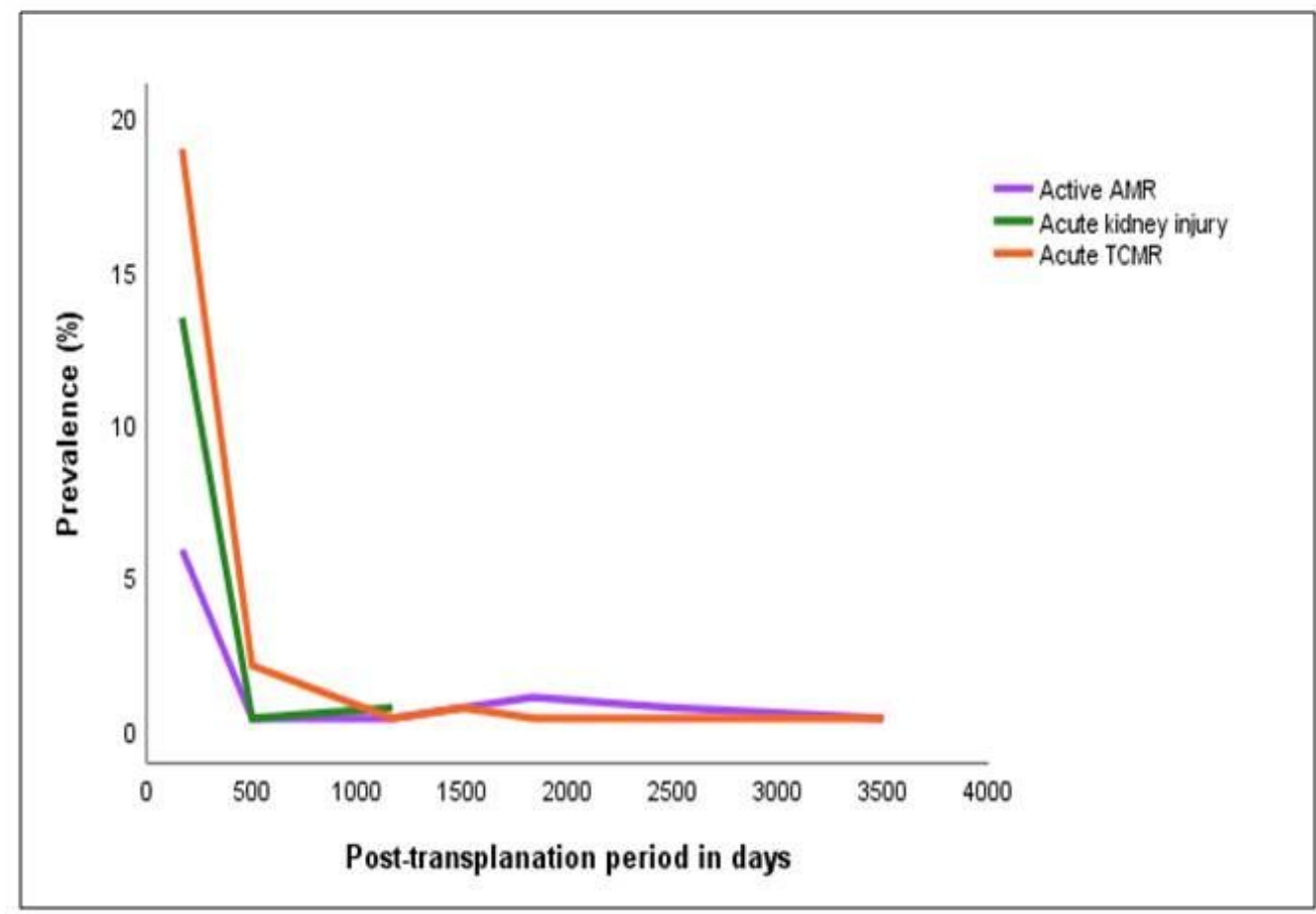

Acute kidney injury and acute TCMR are primarily first year changes, with rare late occurrences. Active AMR began in the first year and was found at a rate of about $8 \%$ of both early and late biopsies. Abbreviations: AMR, antibody mediated rejection; TCMR, T cell-mediated rejection.

\section{Figure 3}

Active AMR began to be seen in the first year and overlapped with the early first year peak of acute TCMR and $\mathrm{AKI}$ (Figure 3). 
Figure 4. Distribution of chronic transplant changes over time.

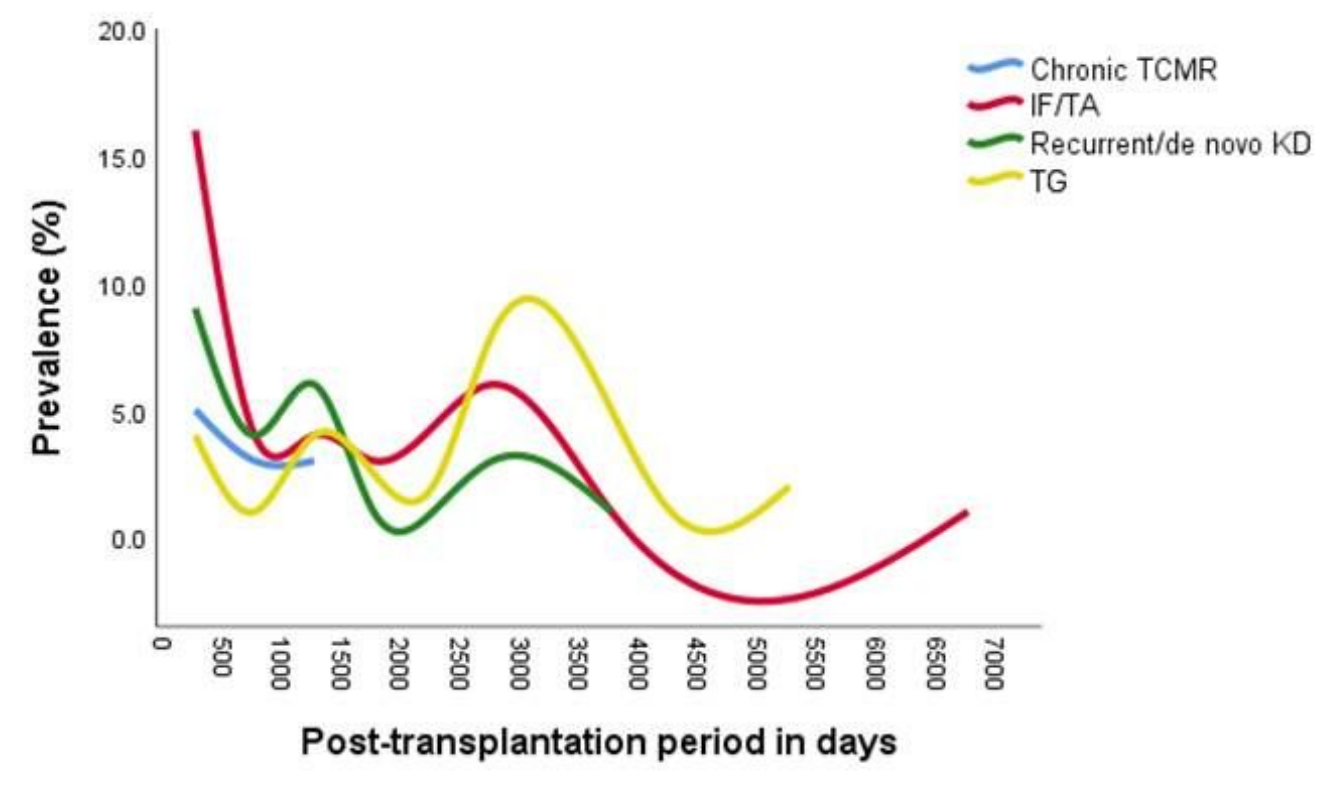

TG and IF/TA were the major causes of late graft dysfunction and were found at the end of the first year and up to 18 years post-transplantation. Abbreviations: TCMR, T cell-mediated rejection; IF/TA, interstitial fibrosis and tubular atrophy; KD, kidney disease; TG, transplant glomerulopathy.

Figure 4

Figure 4 compares the frequency of diagnosis of the chronic conditions of TG, IF/TA, chronic TCMR, and recurrent or de novo KD. The most common diagnoses in the late period were IF/TA at $23.7 \%$ and TG at $19.6 \%$, with a ratio of active AMR to TG of $1: 2.4(42 \%)$. 